\title{
Land use Impacts on Hydrogeomorphology of Lakes in the Upper Benue Valley Area of Adamawa State, Nigeria
}

\author{
Yonnana Ezekiel, Hyellamada Jerry S. \\ Department of Geography, Adamawa State University, Mubi, Nigeria \\ ezekiely97@gmail.com
}

\begin{abstract}
This paper examines the impacts of Land use activities on the Hydrogeomorphic characteristics of Lakes in the Upper Benue Valley Area of Adamawa State. Four major lakes in the area were purposively sampled out for the study based on their apparent sizes and relevance. The study involved an assessment Land Use/Land Cover changes in the area from 1987 to 2013 using Landsat TM Imagery of 1987 and Landsat ETM+ imageries of 1998 and 2013, as well as identification of major human impacts on hydrologic and geomorphic characteristics of the lakes by field observation and interview schedule. Using Purposive Sampling Method, 60 respondents were selected from a settlement in the vicinity of each of the lakes for interview schedule. Results showed that vegetation cover in the area decreased by 30,696.43Ha from 1987 to 1998 and further decreased by 16, 015.50Ha from 1998 to 2013, while farmlands increased by 169, 303.57 Ha from 1987 to 1998 and further increased by 16, 549.41 Ha from 1998 to 2013. Surface water bodies decreased by 533.85Ha from 1987 to 1998 and further decreased by 800.78Ha from 1998 to 2013. Deforestation, farming practices and urbanization were identified as major human activities, affecting the hydrogeomorphology of lakes in the area through the enhancement of runoff, sediment and pollutants loading into the lakes. Monitoring siltation rates and dredging are recommended as sustainable measures for the lakes.
\end{abstract}

Keywords: Hydrogeomorphology, Lakes, Land use/Land covers Changes, Sediment loading, Human activities.

\section{INTRODUCTION}

Studies on lake basins and their associate fluvial features and processes are of much interest to geomorphologists, limnologists, hydrogeologists, hydrologists, ecologists and aquaculturists alike and as well form part of the scope of hydrogeomorphology as an emerging science. Besides streams, lakes are surface water bodies that are of great significance to humans and many other floral and faunal species. They are not just landforms of esthetic beauty but vital resources for human development and societal well being in terms of water supply for human and livestock consumption, domestic uses and irrigation. They also serve as significant socio-cultural sites for fishing festivals, sacred and recreational activities. As components of surface water systems so important to humans, lakes are constructed in both areas of water scarcity and excesses. In the case of water scarcity, artificial lakes (reservoirs) store water during times of abundance for use in times of scarcity when it may not be available, while in the case of excess water, reservoirs provide humanity with a means of temporarily storing excessive quantities of water, as a means of preventing downstream property damage or human deaths (United Nations World Water Assessment Programme, 2010).

However, owing to intense anthropogenic impacts through excessive exploitation of land and water resources, lakes are directly or indirectly subjected to gradual degradation as well as loss in hydrological potentials over time. They experience basin degradation and shrinkages in their water contents (volume and surface area) resulting from the combined influences of catchment erosion and deposition associated with human activities such as deforestation, farming practices and urbanization among others as well as climate change. Gasiorowski, (2008) noted that catchment land uses and climatic conditions are among the major determining factors of lakes sedimentation. It was also observed that lake Quinghai (China) have experienced significant shrinkage in its water level and surface area at rates of $5.28 \mathrm{cmyr}^{-1}$ and $4.38 \mathrm{~km}^{2} \mathrm{yr}^{-1}$ between1959 and 2010 , owing to trends of anthropogenic influences and warming climate (Dong and Song, 2011). 
Lake sedimentation is a gradual and natural modification process of lake basins which occurs over thousands of years. But Helfrich et. al., (2006)

Lake sedimentation is a gradual and natural modification process of lake basins which occurs over thousands of years. But Helfrich et. al., (2006) (2006) argued that, when enhanced by human activities, rapid sedimentation can result to high rates of changes in the lake's morphology over shorter periods and eventually lead to premature extinction. They added that lake sediments can originate from within the lake itself but more often from external sources through poor agricultural practices, highway construction, logging, and land development activities. Erosion caused by excavation within the lake basin, and deforestation on steep shoreline slopes can cause shoreline changes and sediment focusing. Arnaud and Church (1997 in Schiefer and Immell, 2012) observed that significant increase in the sedimentation of West Coast Lake, Vancouver, British Colombia result from anthropogenic activities which include forestry related disturbances and construction works and mining. Many Florida lake basins have been modified to decrease the range of fluctuation in lake levels and reduce the risk and extent of flooding around lakes (Schiffer, 1998).

Adamawa State is blessed with numerous lakes from which vast resources and means of livelihood are tapped; yet, not until recently, little or no attention was given on monitoring the Hydrogeomorphic status of the lakes for sustainable use. However, the few recent works on the lakes include those of Yonnana et al., (2014), Bashir and Mahmud (2015), Yonnana et al., (2015) and Shinggu et al., (2015). Unlike countries such as India, where the government have constituted Lake Development Authorities at State levels to handle issues on management, utilization and sustainability of lakes (Gopal et. al., 2010), efforts towards management and improvement of most lakes for sustainable use in Nigeria have not been satisfactory.

Therefore, considering the relevance of lakes as significant freshwater resources to man and vital components of the ecosystem on one hand and their occurrence as dynamic features of the landscape whose occurrence periods could be shortened by degradation processes, on the other hand, there is need to comprehend their dynamic trends on temporal scales. Also, considering facts that the current state of most lakes in the world is alarming such that degradation of the world's lakes is now a serious global water resources issue (United Nations World Water Assessment Programme, Oct 1, 2010), there is an urgent need for their conservation and efforts in reversing their degradation trends by individuals, communities, governmental and non-governmental agencies alike.

The study area lies between latitudes $09^{\circ} 09^{\prime} 00^{\prime \prime} \mathrm{N}$ and $09^{\circ} 33^{\prime} 00^{\prime \prime} \mathrm{N}$ of the equator and between longitudes $12^{\circ} 21^{\prime} 00^{\prime \prime} \mathrm{E}$ and $12^{\circ} 54^{\prime} 00^{\prime \prime} \mathrm{E}$ of the Prime Meridian (Fig. 1), covering a total area of about 266, 925.5Ha (Federal Surveys, Nigeria 1971).

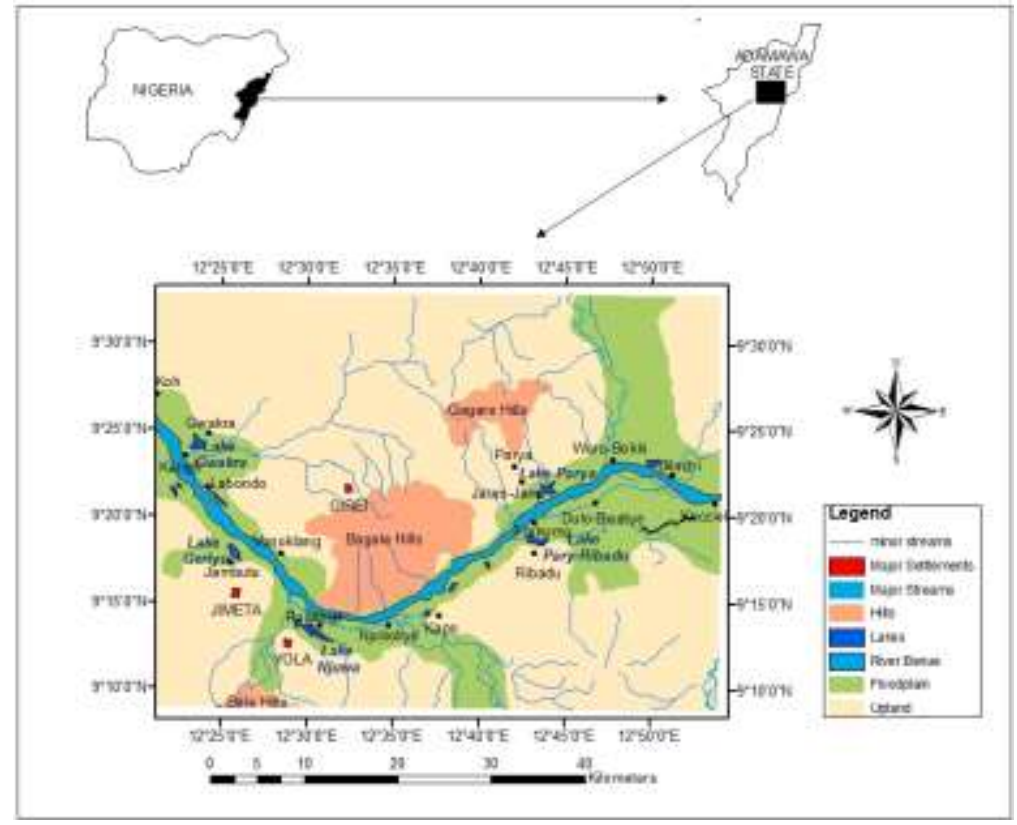

Figure1. Study Area 
The area is characterized by humid tropical climate; marked by distinct wet and dry seasons, as determined by the year movements of Inter-Tropical Convergence Zone (ITCZ). The wet season lasts for about five (5) to Six (6) months with annual precipitation values ranging from $656.70 \mathrm{~mm}$ to $1113.30 \mathrm{~mm}$ (UBRDA Yola, 2013). Major sources of water for the lakes include Runoffs and streams which take their sources from uplands and cut across major built-up areas and almost all farmlands in the area, floods from the River Benue and underground inputs. The area is predominated by ferruginous tropical soils of sandy parent materials, non-differentiated lithosols and lithic soils, as well as non-differentiated vertisols, and mineral hydromorphic soils in combination with juvenile soils on recent riverine and lacusterine alluvium (Bawden and Tuley 1966). It falls under the Sudan Savanna vegetation belt of Nigeria which is a combined zone of Sudan and sub-Sudan vegetation types, much of which is subjected to regular cultivation (Bawden and Tuley 1966). Floral species of the area are categorized on life-form basis into arboreal and aquatic vegetation forms. The predominant arboreal vegetation species of the area include Vitelleria paradoxa (shear butter), Parkia biglobosa (locust bean) Tamarinus indica (Tamarin), Acacia albida, Zizipus spp, and Prosopis spp among others, while the aquatic forms are sub-grouped into Emerged Macrophytes, Floating Macrophytes, Submerged Macrophytes and phytoplankton (Alga spp) for easy identification sake. The area is geologically characterized by Albian Feldspathic and Calcareous sediments (Bima Sandstones) formed in the Cretaceous period (Kogbe, 1981; Bawden, 1972). Overlying the sandstones of the area are two major forms of Quaternary marine deposits - Benue valley alluvium and recent river alluvium (Bawden and Tuley 1966), within which the lake basins were formed.

\section{Materials AND Methods}

Landsat TM imagery of November 1987 and Landsat ETM November 1998 and 2013 (Table 1) were used for land use/Land cover data acquisition and change detection. The adoption of this approach was based on the notion that changes in the area's land use/land cover are capable of posing either direct or indirect influences that could alter the lakes basin morphologies and their water quality statuses.

Table1. Properties of images used

\begin{tabular}{|l|l|l|l|l|l|l|}
\hline S/No & Image & Sensor & Resolution & $\begin{array}{l}\text { Date } \\
\text { acquisition }\end{array}$ & Source & Bands \\
\hline 1 & Landsat 111987 & ETM+ & $30 \times 30 \mathrm{~m}$ & $07 / 04 / 2011$ & GLCF & 3,4 and7 \\
\hline 2 & Landsat 11 1998 & ETM+ & $30 \times 30 \mathrm{~m}$ & $07 / 04 / 2011$ & GLCF & 3,4 and7 \\
\hline 3 & Landsat 112013 & ETM+ & $30 \times 30 \mathrm{~m}$ & $07 / 04 / 2011$ & GLCF & 3,4 and7 \\
\hline
\end{tabular}

The land use/land cover changes in the study area over a period of Twenty five (25) years (1987 to 1998 and 1998 to 2013) were assessed by Supervised Classification Change Detection Technique (Lu et al 2004). Color composites of the images were developed in ILWIS 3.7 environment using Bands 3 , 4 and 7 of the Landsat-TM images. Since Composite images were already georeferenced and geocoded, portions of the study area were sub-mapped on the same ILWIS environment and subsequently subjected to Supervised Classification procedures. The classified images were then exported to IDRISI Taiga software where they were reclassed and used for Area Change Detection. The reclassed images were then exported to ArcGIS 9.2 for visual enhancement and production of final output.

Based on proximity to each of the lakes, a settlement was purposively selected for interview schedule on human activities and associated morphological changes in the lakes. Going by preliminary survey were an average of 200 people were found to be engaged in various forms of activities within and around each of the lakes, a sample of 60 respondents $(30 \%)$ was also purposively selected for the interview schedule on each of the lakes. The interview schedule was then complimented by observation and recording of major human activities affecting the lakes' Hydrogeomorphic characteristics.

\section{RESUlTS AND DisCUSSION}

\subsection{Land use/Land Cover Changes in the Area}

The area was found to be influenced by four major land use/land cover types (farmlands, built-up areas, vegetation cover and water bodies). Changes in these land use/land cover types as influenced by 
direct or indirect human activities were found to have some impacts on both the basin morphology of the studied lakes as well as on their water quality statuses. Change detection results showed that the area's vegetation cover decreased from $22 \%$ in 1987 to $10.6 \%$ in 1998 , owing to human encroachment for farmlands and settlement purposes.

The vegetation cover further decreased from $10.6 \%$ in 1998 to $4.6 \%$ in 2013 (Table 2). Farmlands showed greater increase from $76.3 \%$ in 1987 to 87.8 in 1998 and $94 \%$ in 2013. Field study in 2013 confirmed these predictions, as most parts of the study area known to be covered by dense vegetation in the past have been transformed into cereal and legume farmlands in the recent times. These changes are mainly tied to increase in human pressure on land, search for fertile farmland and fuel wood exploitation. Change in built-up areas was found to be little or gradual increase from $0.3 \%$ in 1987 to $0.5 \%$ in 1998 and $0.6 \%$ in 2013 . This is an indication that more land was used for crop production than human settlement development.

Table2. Land use/Land Cover Changes from 1987 to 2013

\begin{tabular}{|l|l|l|l|}
\hline Land Cover Type & $1987(\mathrm{Ha})$ & $1998(\mathrm{Ha})$ & $2013(\mathrm{Ha})$ \\
\hline Vegetation & $58990.53(22 \%)$ & $28294.10(10.6 \%)$ & $12278.6(4.6 \%)$ \\
\hline Build-up Areas & $800.78(0.3 \%)$ & $1334.63(0.5 \%)$ & $1601.5(0.6 \%)$ \\
\hline Water Bodies & $3470.03(1.3 \%)$ & $2936.18(1.1 \%)$ & $2135.4(0.8 \%)$ \\
\hline Farmlands & $203664.16(76.3 \%)$ & $234360.59(87.8 \%)$ & $250910(94 \%)$ \\
\hline
\end{tabular}

The temporal reduction in vegetation cover and its replacement by farmlands and built-up areas as presented in Table 2 and clearly portrayed Figs. 2, 3 and 4 result to the generation of sediment and pollutants, which are eventually transported by run offs into the lakes. A most significant situation is the case of Jiberu Drainage system which cuts across many farmlands transporting huge quantities of sediment into Lake Gwakra (Fig. 5). This situation is similar to the findings of Shiefer and Immell (2012) in their work 'land use impacts on lake sedimentation in the Central Rocky Mountain Foothills'

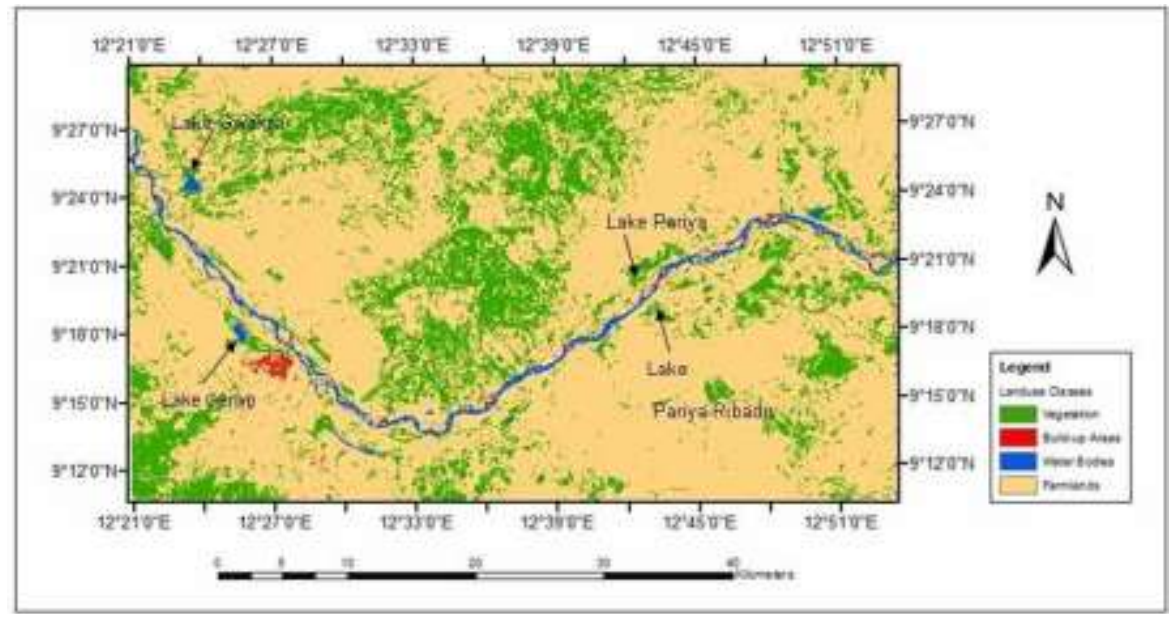

Figure2. Land use/Land Cover Classes of the Study Area in 1987.

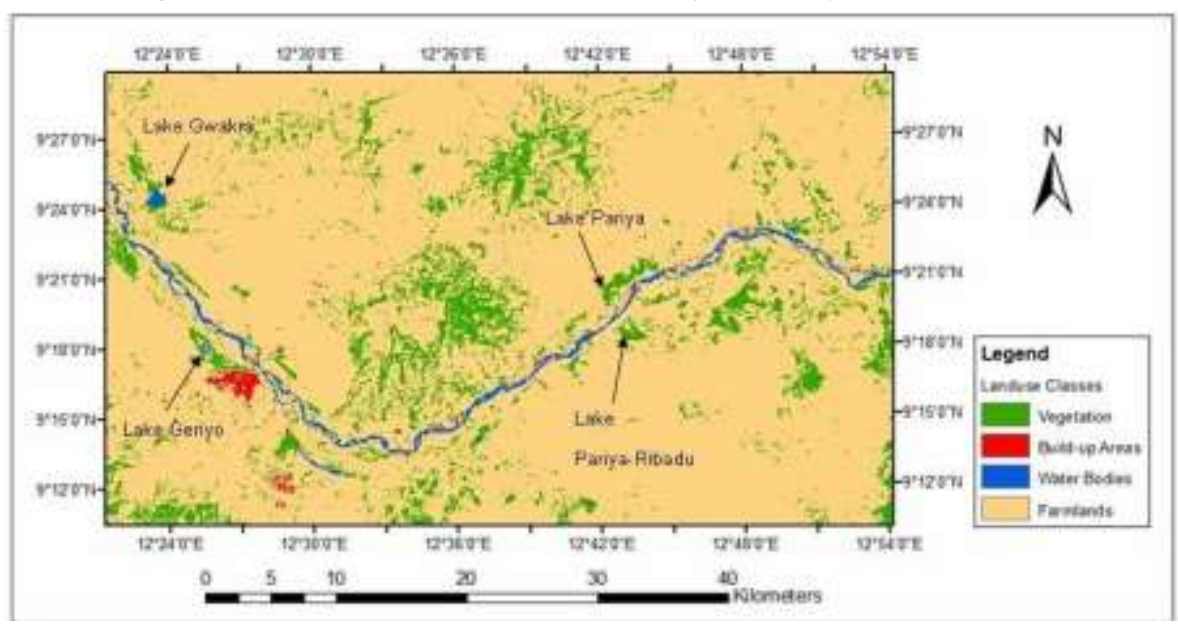

Figure3. Land use/Land Cover Classes of the Study Area in 1998. 
Land Use Impacts on Hydrogeomorphology of Lakes in the Upper Benue Valley Area of Adamawa State, Nigeria

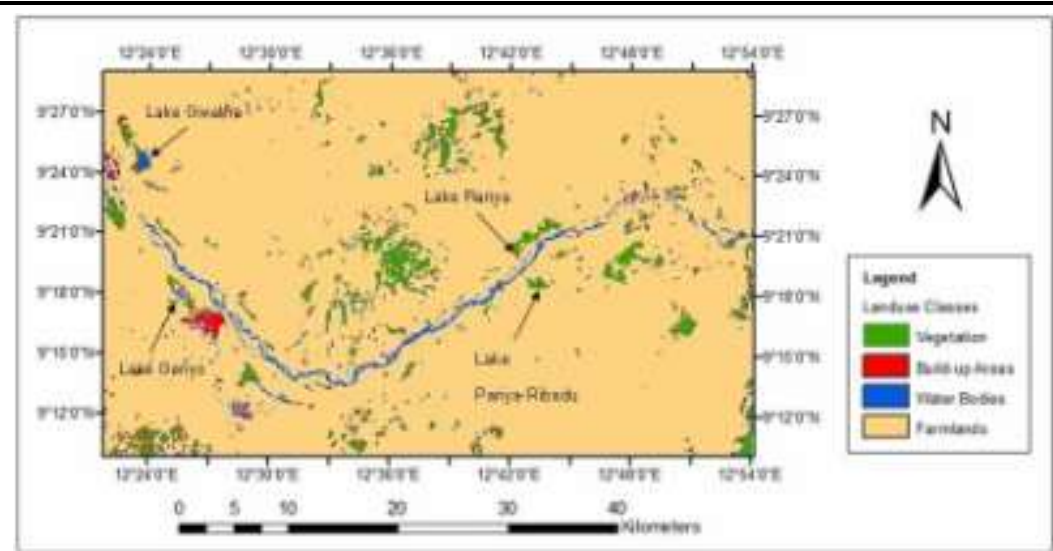

Figure4. Land use/Land Cover Classes of the Study Area in 2013.

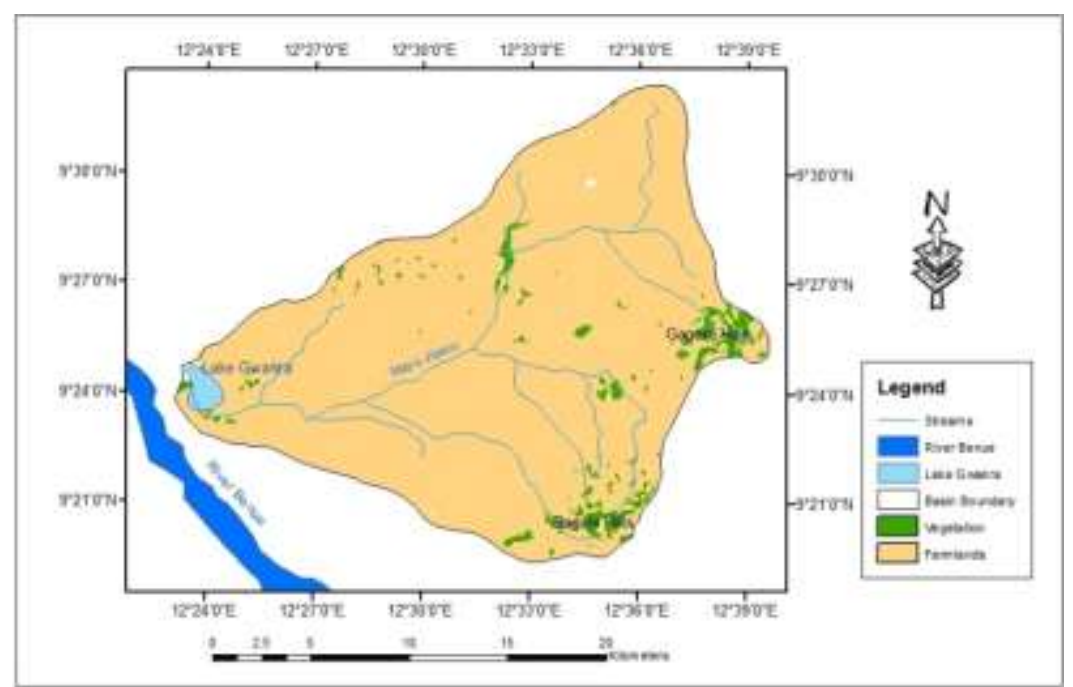

Figure5. The Jiberu Drainage System and associated land use/land cover in 2013

\section{HuMAN IMPACTS ON BASIN MORPHOLOGY OF THE LAKES}

It was gathered from interview schedule that most of the people that engage in socio-economic activities within and around the lakes were of the male folk and have lived in the vicinity of the lakes for more than 24 years (Table 3). As such, they were much conversant with nature of apparent Hydrogeomorphic characteristics of the studied lakes and changes that occurred over the years.

Table3. Biodata of respondents

\begin{tabular}{|l|l|l|l|l|l|l|}
\hline Settlement & \multicolumn{2}{|l|}{ Gender } & \multicolumn{2}{l|}{ Duration of stay in the area } & \multicolumn{2}{l|}{ Educational Status } \\
\hline & Male & Female & $\leq 24$ Years & $>24$ Years & $\begin{array}{l}\text { Formal } \\
\text { Education }\end{array}$ & $\begin{array}{l}\text { Non-Formal } \\
\text { Education }\end{array}$ \\
\hline Kangli (Gwakra) & $47(78.3 \%)$ & $13(21.7)$ & $26(43.3 \%)$ & $34(56.7 \%)$ & $37(61.7 \%)$ & $23(38.3 \%)$ \\
\hline Geriyo & $47(78.3 \%)$ & $13(21.7)$ & $30(50 \%)$ & $30(50 \%)$ & $41(68.3 \%)$ & $19(31.7 \%)$ \\
\hline Ngurore (Ribadu) & $50(83.3 \%)$ & $10(16.7)$ & $20(33.3 \%)$ & $40(66.7 \%)$ & $21(35 \%)$ & $39(65 \%)$ \\
\hline Jauro-Jam (Pariya) & $46(76.7 \%)$ & $14(23.3 \%)$ & $22(36.7 \%)$ & $38(63.3 \%)$ & $28(46.7 \%)$ & $32(53.3 \%)$ \\
\hline
\end{tabular}

Field studies further revealed that farming practices involving land tillage and use of various forms of agrochemicals to clear existing vegetal cover and soften the land for crop production on annual basis were among the predominant human activities in the area. By these activities, affected farmlands were exposed to sediment detachment and entrainment by rain drops and surface wash into fluvial systems, which either drain directly in the lake basins or onto their floodplains before being subsequently washed into the lake basins. The annual occurrences of these processes have always resulted to gradual sedimentation or siltation of the lake basins, thus causing changes in their morphologies.

Encroachment of farming practices onto littoral zones of the studied lakes which involves clearing and tillage of such zones, was identified as another important human impact on basin morphology of lakes in the area. It was observed that lake zones engaged in such activity are generally shallow, void of natural littoral vegetation and flooded at periods of high water levels, due to continual disturbance 
by cultivation practices (Plate I). The shallow state of the zones is highly influenced by human accelerated sediment focusing through the continual land tillage. This activity contributes immensely to deformation of the lakes' basin morphology over time and is most common to Lakes Gwakra and Geriyo at periods of irrigation farming in dry seasons. In addition, stirring of lake waters by livestock (cattle) either during water uptake or crossing the lake and massive disturbances during fishing festival also enhance serious sediment focusing and alteration of the lakes' basin morphology.

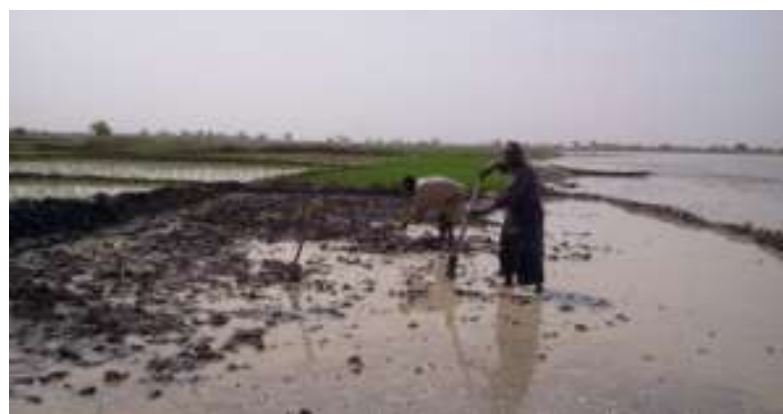

PlateII. Impacts of farming activities on the Littoral zone of Lake Gwakra

Other human impacts on the basin morphology of lakes in the study area as observed from field study included direct deformation of lake banks through the construction of water canals; canoe harbors; and creation of water drinking points for livestock and fish trapping.

The interview schedule unveiled that changes in Surface Areas of the lakes over the years were in the form of fluctuations rather than continual decrease. The changes in Surface Areas of the lakes were a greater extent tied to variability in rainfall regime of the study area and its environs over the years. Most respondents attributed changes in Depths of the lakes to sedimentation (Table 4).

Table4. Respondents' perceptions on changes in Surface Areas and Depths of the Lakes

\begin{tabular}{|c|c|c|c|c|c|c|}
\hline Settlement & \multicolumn{3}{|c|}{ Type of change in Lake Surface Area } & \multicolumn{3}{|c|}{ Cause of Change in Lake Depth } \\
\hline & Decrease & Increase & Fluctuation & Sedimentation & $\begin{array}{l}\text { Fluctuation in } \\
\text { Lake Level }\end{array}$ & Both \\
\hline Kangli (Gwakra) & $\begin{array}{l}17 \\
(28.3 \%)\end{array}$ & $3(5 \%)$ & $40(66.7 \%)$ & $42(70 \%)$ & $8(13.3 \%)$ & $\begin{array}{l}10 \\
(16.7 \%)\end{array}$ \\
\hline Geriyo & $24(40 \%)$ & $2(3.3 \%)$ & $34(56.7 \%)$ & $31(51.7 \%)$ & $2(3.3 \%)$ & $27(45 \%)$ \\
\hline Ngurore (Ribadu) & $18(30 \%)$ & $1(1.7 \%)$ & $41(68.3 \%)$ & $31(51.7 \%)$ & $8(13.3 \%)$ & $21(35 \%)$ \\
\hline Jauro-Jam (Pariya) & $21(35 \%)$ & $8(13.3 \%)$ & $31(51.7 \%)$ & $38(63.3 \%)$ & $12(20 \%)$ & $10(16.7)$ \\
\hline
\end{tabular}

\section{IMPACTS OF HUMAN ACTIVITIES ON THE LAKES WATER QUALITY}

A wide range of human activities were found to be responsible for the lakes' poor water quality statuses as established by Yonnana (2015). However, the most salient activities identified included non-regulated use of agro-chemicals for farming, discharge of various forms of effluents from nearby human settlements, waste disposal around lake areas and direct pollution of the lakes' water mostly by animal grazing.

Having established that the area is dominated by farmlands, it was further observed that the use of agro-chemicals is a major farming practice in the area (Plate II). Since most of the chemicals are water-based or soluble in water, they are easily washed away from farm sites by either surface wash or percolation and end up contaminating valuable surface water sources of the area; the lakes inclusive.

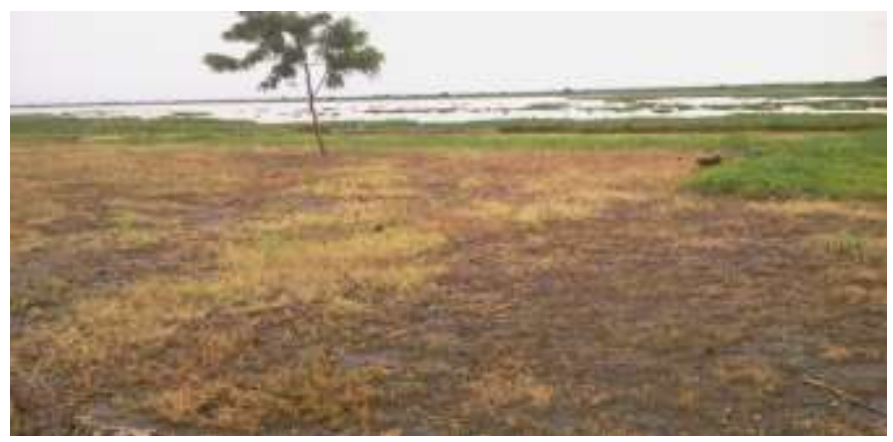

Plate II. Eminence of the use of Agro-chemicals around Lake Geriyo 
Sprawl in human settlements as established by change detection analysis, signifies increase in human population and in turn increase in generation of waste that contribute to degradation of the lakes. It was observed that one of the major inlets of Lake Geriyo connects numerous sewage channels from Jimeta Metropolis which expose the lake to contamination by urban sewage. Similarly, the proximities of the other lakes to settlements like Kangli, Gwakra, Ribadu, and Pariya also portrayed the same implications.

\section{Conclusion}

Lakes in the Benue Valley area of Adamawa State are undergoing serious state of degradation in basin morphology, water quantity and quality despite their life sustaining relevancies. This may eventually have serious effects on the livelihoods of large human and livestock populations that have direct or indirect dependence on the lakes. Therefore, the urgent need for further inventory, restoration and revitalization of all the lake resources of Adamawa State is a general responsibility resting on the shoulders of all stake holders partaking in the benefits provided by the lakes.

Therefore, Bathymetric Surveys and mapping of lakes in the state are recommended on regular interval time scales for quantifiable monitoring of changes in their morphological characteristics. Where high levels of siltation are observed, dredging in order to revitalize water collection for sustainable uses. Policies on landuse activities that pose serious danger on the lakes as well as adequate planning for discharge of effluents into the lakes should established.

\section{REFERENCES}

[1] Akosim, C., Shitta, A.E., Kwaga, B.T. \& Inah, E.I. (2007) Avifauna Diversity and Status of some Wetlands in Adamawa State, Nigeria. ASSET Series B. 6(1); 89-107.

[2] Bashir, A. and Mahmud, I. (2015) Assessment of Changes in Landuse/Land Cover and Morphology of Lake Njuwa, Yola Adamawa State, Nigeria, International Journal of Engineering Sciences and Research Technology 4(2); 31-40. www.ijesrt.com

[3] Bawden, M. G. (1972). Physiography, Geology, Geomorphology and Hydrology. In Tuley, P. (ed). Land Resources of North East Nigeria. Vol. 1; The Environment: Land Resource Study No.9. Surrey, England. Land Resources Division/Overseas Development.

[4] Bawden, M. G. \& Tuley, P. (1966). The Resource of Southern Sardauna and Southern

[5] Adamawa Provinces, Northern Nigeria: Land resource Study No. 2. Land Resources Division/Overseas Development.

[6] Dong, H. \& Song, Y. (2011 May 20). Shrinkage History of Lake Qinghai and Causes during the last 52 years. 2011 Water Resources and Environmental Protection international Symposium Book of Proceedings; 446-449.

[7] Federal Surveys, Nigeria (1971). Yola Sheet 48. Edition 1

[8] Gasiorowski, M., (2008). Deposition Rate of Lake Sediment under Different Alternative Stable States. Retrieved April 25, 2012 from http://www.geochronometria.pl

[9] Gopal, B., Sengupta, N., Dalwani, R. \& Srivastava, S. K. (2010). Conservation and Management of Lakes-An Indian Perspective. New Delhi; National Conservation Directorate, Ministry of Environment and Forests.

[10] Helfrich, L. A., Parkhurst, J. and Neves, R. (2006). Guide to Understanding and Managing Lakes: Part I (Physical Measurements).Virginia Cooperative Extension. Retrieved September 16, 2012 from http://pubs.ext.vt.edu/420/420-538/420-538.html

[11] Kogbe, C.A., (1981) Major Transgressive Episodes in the Benue Valley of Nigeria. Earth Evolutionary Science 2; 139-143.

[12] National Bureau of Statistics (2010) Annual Abstract of Statistics; 88-90. www.nigerianstat.gov.ng/pages/download/71

[13] Schiefer, E \& Immell, R. (2012). Land Use Impacts on Lake Sedimentation in the Central Rocky Mountains Foothills. Streamline Watershed Management Bulletin Vol. 1 Summer 2012.

[14] Schiffer, D. M. (1998). Hydrology of Central Florida Lakes: A Primer. U. S. Geological Survey in cooperation with The St. John's River Water Management District and The South Florida Water District. Denver, U. S. Government Printing Office. 
[15] Shinggu, D. Y., Maitera, O. N. and Barminas, J.T (2015) Distribution of Organochlorine Pesticides Residue in Fish, Water and Sediment on Lake Gokra Adamawa State Nigeria, Adamawa State University Journal of Scientific Research, 3(1)

[16] Sidle, R. C. and Onda, Y. (2004). Hydrogeomorphology: Overview of an emerging Science. Hydrological Processes. 8(4), 597-602. Doi:10.1002/hyp.1360

[17] Yonnana, E. (2015). Assessment of Hydrogeomorphic characteristics of lakes in the Upper Benue Valley of Adamawa State, Nigeria. Unpublished PhD Thesis, Department of Geography, Modibbo Adama University of Technology Yola, Adamawa State.

[18] Yonnana, E., Tukur, A. L., and Mubi, A. M. (2014) Physicochemical Parameters and Water Quality for Livestock Consumption from Selected Lakes in the Upper Benue Valley Area of Adamawa State, Northeastern Nigeria, International Journal of Health and Medical Information, $3(1) ; 42-47$.

[19] Yonnana, E., Tukur, A. L., and Mubi, A. M. (2015) Morphometric Characteristics of Selected Lakes in the Upper Benue Valley Area of Adamawa State, Northeastern Nigeria, Journal of Geography and Regional Planning, 8(3); 56-64. Doi: 105897/JGRP2014.0470. http://www.academicjournals.org/JGRP

[20] United Nations World Water Assessment Programme (2010). Lakes: Freshwater Storehouses and Mirrors of Human Activities. Retrieved, July 2, 2012 from www.unesdoc.unesco.org/images/0018/001863/186316e.pdf 